\title{
Rapid stepping test towards virtual visual objects: Feasibility and convergent validity in older adults
}

\author{
Yeshayahu Hutzler ${ }^{\mathrm{a}, *}$, Olga Korsensky ${ }^{\mathrm{a}}$ and Yocheved Laufer ${ }^{\mathrm{b}}$ \\ ${ }^{a}$ Academic College at Wingate Institute, Netanya, Israel \\ ${ }^{\mathrm{b}}$ Department of Physical Therapy, Faculty of Social Welfare and Health Sciences, University of Haifa, \\ Haifa, Israel
}

Received 3 July 2016

Accepted 28 July 2016

\begin{abstract}
.
BACKGROUND: Rapid voluntary stepping has been recognized as an important measure of balance control.

OBJECTIVE: The purpose of this study was to assess the feasibility and convergent validity of a Rapid Stepping Test protocol utilizing a virtual reality SeeMeTM system (VR-RST) in elderly ambulatory and independent individuals living in a community residential home.

METHODS: Associations between step execution times determined by the system and the Activities-specific Balance Confidence (ABC) Questionnaire, and clinical measures of balance performance in the MiniBESTest and Timed Up and Go (TUG) test, were established in 60 participants (mean age $88.2 \pm 5.0$ years). All participants completed the study.

RESULTS: The correlations of the ABC questionnaire and the clinical tests with VR-RST forward and backward stepping were moderate ( $\rho$ rage $0.42-0.52$ ), and weak to moderate with sideward stepping ( $\rho$ rage $0.32-0.52$ ). Moderate to strong correlations were found across stepping directions ( $\rho$ rage $0.45-0.87$ ).

CONCLUSION: Findings support the test's feasibility and validity and confirm the utility of the VR-RST as an assessment tool in an elderly population.
\end{abstract}

Keywords: Balance, assessment, aging

\section{Introduction}

Non-fatal injuries, such as lacerations, hip fractures, and head traumas, which can negatively affect the quality of life and increase the risk of early mortality, are a major health concern due to the growing incidence of falling in the elderly population [1-3]. In addition to the personal threat to these individuals, falls also make up a considerable amount of the elderly's medical expenses [4]. In the U.S., for example, medical expenses due to falls reached about 20 billion dollars in the year 2000 [5], and grew to well over 30 billion dollars in 2013 [6]. According to the U.S. Census Bureau [7], individuals older than 85

\footnotetext{
${ }^{*}$ Corresponding author: Yeshayahu Hutzler, Graduate School, Academic College at Wingate, Wingate Institute, Netanya 42902, Israel. E-mail: shayke@wincol.ac.il.

0928-7329/17/ $\$ 35.00$ C) 2017 - IOS Press and the authors. All rights reserved

This article is published online with Open Access and distributed under the terms of the Creative Commons Attribution NonCommercial License (CC BY-NC 4.0).
} 
are considered a unique group and are termed "oldest old" adults, comprising nearly $14 \%$ of the total population older than 65 .

Impaired balance is commonly considered a primary cause for falling in the elderly, and the risk of falling increases with age $[6,8]$. Balance control involves a complex neuromuscular process, demanding somatosensory, vestibular, and visual input in reference to the environment, in order to keep the body upright and the line of gravity within the boundaries of the base of support [9-12]. Balance control is characterized by dynamic, adaptive processes, including (a) proactive (self-initiated and automatically processed) control, mostly in reference to visual stimuli utilized for surveying the environment for potential barriers and for preparing a stabilizing strategy in advance, and (b) reactive balance control, which is characterized by actions in response to unexpected external perturbations, which are generally perceived through somatosensory stimuli [13]. Each control system contributes to balance control according to the demands and to the availability of the information. In addition, when one system is deficient the other system may compensate [11].

There are several strategies for responding to balance perturbations; the most commonly used are ankle and hip strategies [12]. When the ankle and hip strategies are insufficient to prevent a fall that occurs particularly when perturbations are unexpected and of large amplitude, rapid stepping resulting in "change in support" is necessary [14]. This is the most effective way to prevent falling [15], but rapid step execution is often impaired in the elderly [16-18]. Therefore a rapid step execution test (RST) utilizing a somatosensoric cue and force plate measures has been utilized to identify rapid step response time of elderly individuals at risk for falls. These measures were able to differentiate between fallers and non-fallers, while the use of functional tests such as the Berg Balance Scale (BBS) and the Timed Up and Go test (TUG) are less conclusive [19]. In follow-up studies, the RST measure was found to be valid [20] and reliable [21]. However, force platform assessments are often not feasible in the clinical setting, due to cost and technological issues. Therefore, efforts have been made to enable the utilization of RST execution within a more simple, user-friendly, and inexpensive test environment. One solution for low-cost devices is stepping plates on the floor attached to a video screen [22,23].

Virtual reality (VR) systems have acquired an exponentially growing interest in rehabilitation, with almost two-thirds of the scholarly contributions published about VR systems in rehabilitation directed toward stroke survivors and the elderly as the main end-users [24-26]). The effectiveness of utilizing VR technology as an intervention for facilitating mobility and balance after stroke has been established in a meta-analysis of 16 randomized studies, with a marked effect size after VR training in participants compared to controls being reported [27]. In addition, the usefulness of this technology for measuring fall risk in older people has recently been signaled with a specifically designed stepping choice reaction time test [28]. SeeMe ${ }^{\circledR}$ Brontes Processing (Gliwice, Poland), an off-the-shelf VR evaluation and training system that can be tailored by the operating clinician to the capabilities of individuals with impairments [22-24], was developed by a physiotherapist team during the first decade of the 21 st century and reliably applied for upper extremity reaching [29]. However, until now, no RST has been described utilizing on an off-the-shelf VR platform using only a computer, a video camera, and a screen. Following preliminary results with the SeeMe VR system, previously presented in a conference poster [30], the objectives of the present study were to assess RST in the forward, sideward, and backward directions, and to inform the convergent validity of these tests by means of associations between step execution time as determined by the SeeMe system and clinical measures of balance performance and fear of falling. A secondary purpose was to assess the impact of age across measures. 
Table 1

Participants' background variables

\begin{tabular}{lccc}
\hline & All & $\geqslant 86$ & $\leqslant 85$ \\
\hline$N$ of participants (males/females) & 60 & $42(8 / 34)$ & $18(4 / 14)$ \\
Age (Mean \pm SD) & $88.2 \pm 5$ & $90.7 \pm 3.5$ & $82.3 \pm 2.3$ \\
$N$ falling in past year & 18 & 14 & 4 \\
$N$ using assistive devices at home & 10 & 9 & 1 \\
$N$ using assistive devices outside the home & 21 & 19 & 2 \\
$N$ (Mean \pm SD) of exits from residence & $4.2 \pm 5.2$ & $6.2 \pm 5.4$ & $1.2 \pm 4.8$ \\
$N$ (Mean \pm SD) of weekly physical activity sessions & $7.1 \pm 1.9$ & $8.1 \pm 1.8$ & $1.76 \pm 2$ \\
\hline
\end{tabular}

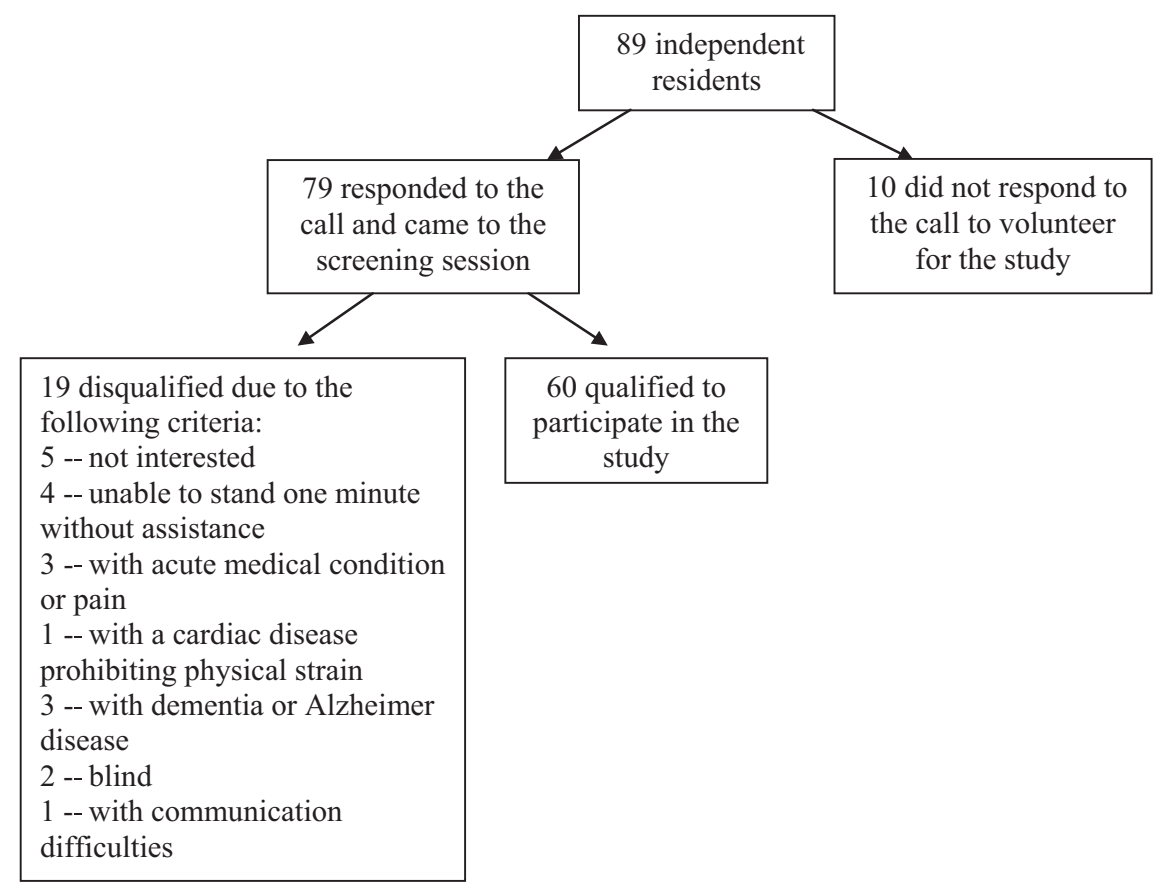

Fig. 1. Selection of participants to the study.

\section{Methods}

\subsection{Participants}

All independent residents of a senior living retirement center targeting a middle-class Caucasian population were invited to participate in this study. Sixty volunteers (mean age $88.2 \pm 5.0$ years) residing in this center participated in the study. The inclusion criteria were: (a) age above 65; (b) able to walk independently with/without assistive devices; (c) able to respond to auditory and visual instructions and stimuli; and (d) willing to sign the consent form. The exclusion criteria were: (a) medical conditions prohibiting the ability to perform the MiniBEST balance test [31,32]; and (b) having an acute injury, a disease, or acute pain. Figure 1 describes the participants' selection process. Our sample included a large cohort of "oldest old" adults, and in order to reflect the specific sensitivity of our system for balance control with growing age, the RST and clinical balance outcomes within our sample were compared across age subgroups. The participants were divided into two subgroups of participants: aged 85 and below 


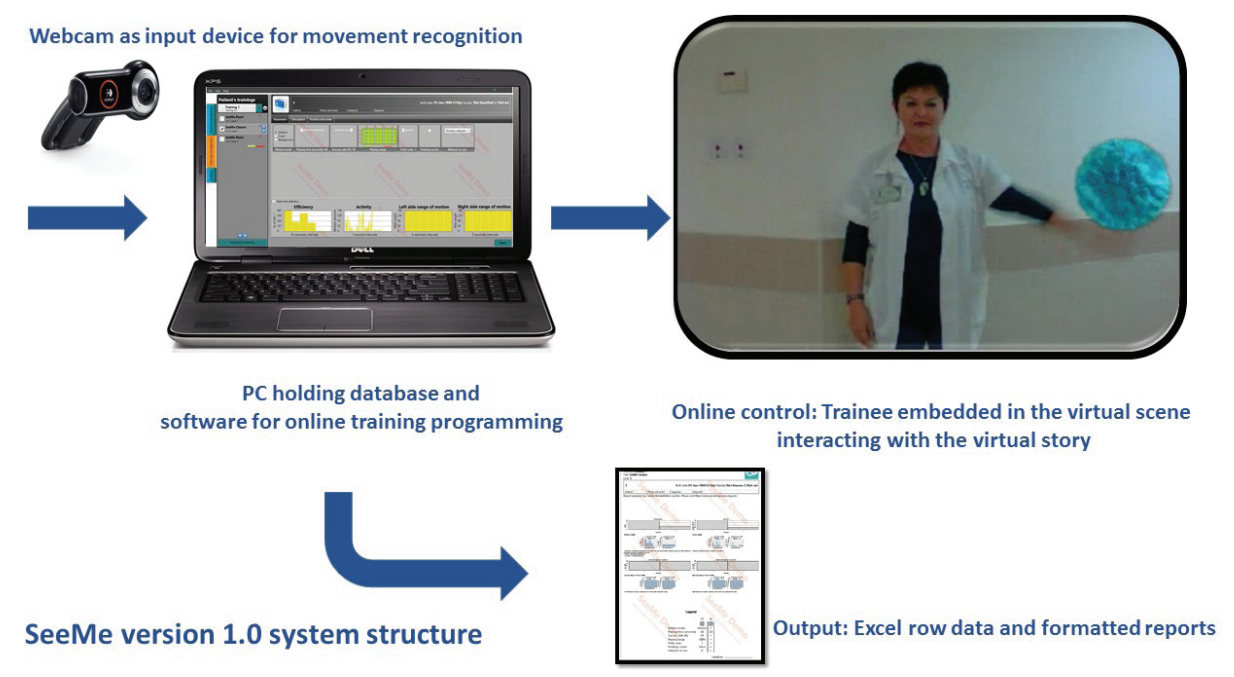

Fig. 2. SeeMe system structure.

( $n=18: 4 \mathrm{M} ; 14 \mathrm{~F}$ ), and aged 86 and above ("oldest old"; $n=42: 8 \mathrm{M} ; 34 \mathrm{~F})$. Table 1 describes the participants' background variables related to their functional and community participation details relevant to balance and mobility. The study was approved by the Institutional Ethical Review Board of the Faculty. An informed consent form was signed by all the individuals participating in the study.

\subsection{Instruments}

\subsubsection{SeeMe platform}

SeeMe ${ }^{\circledR}$ Version 1.0 (Brontes Processing, Gliwice Poland) is a clinician-controlled exercise and assessment system utilizing projected video capture by means of a webcam and Microsoft Kinect technology, a PC, and a 42-inch LCD screen. The design and structure of the SeeMe system are demonstrated in Fig. 2. The off-the-shelf system consists of several games.

\subsubsection{VR react game}

In this game, virtual balls appear randomly at predetermined distances on both sides of the screen (see Fig. 3). In this task the participant touches the virtual ball with his/her arm or foot. The system records the response time and the number of correct actions vs. misses. In the current study a specific setup and protocol of this game was used, labeled the Virtual Reality Rapid Stepping Test (VR-RST). This protocol included one $90 \mathrm{sec}$ training session, and three $60 \mathrm{sec}-$ long testing sessions of the React game within the SeeMe VR platform.

The game was projected on a 42-inch TV screen. A webcam was located $50 \mathrm{~cm}$ above the floor, $150 \mathrm{~cm}$ away from the participant, who stood within a $30 \mathrm{~cm}$ square area marked with tape on the floor. The camera was rotated at an angle of 30 degrees toward the highlighted square. Four sets of trials were programmed and executed, the first (a) for habituation and the others (b-d) for measurement:

(a) A $90 \mathrm{sec}$ acclimatization game, in which each participant gained some experience with the game environment. The participant interacted with the game for $30 \mathrm{sec}$ while facing the camera and executing side stepping. This was followed by two periods of $30 \mathrm{sec}$ facing the screen with either the left or right side of the body, and executing forward and backward steps with the right and left foot, as appropriate; 


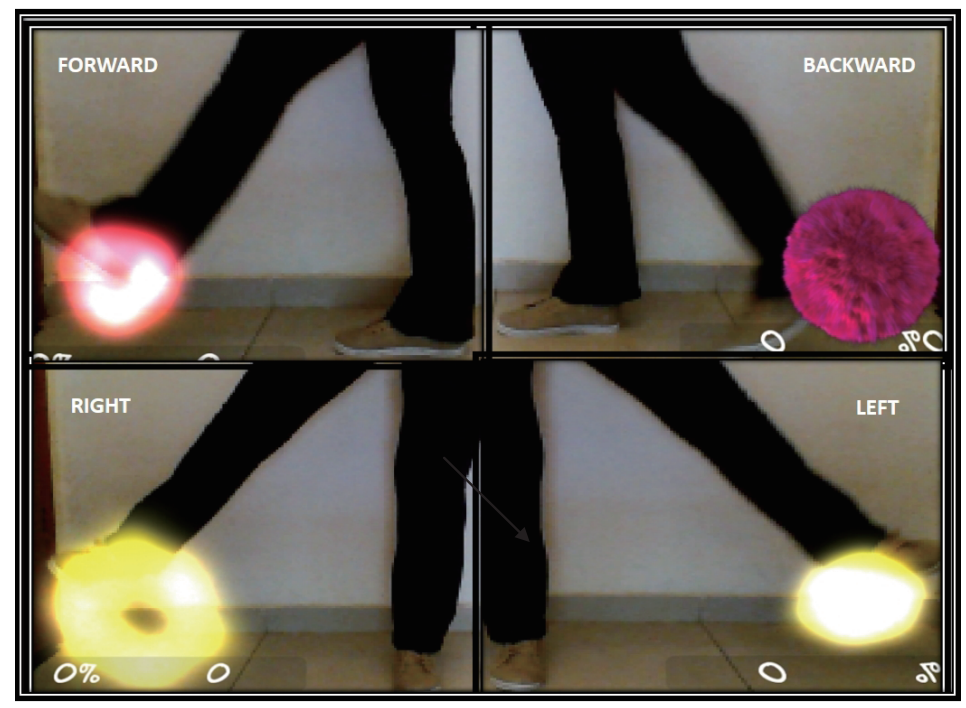

Fig. 3. Step test in the SeeMe system.

(b) A $60 \mathrm{sec}$ series of game interactions at the frontal plane;

(c) A $60 \mathrm{sec}$ series of game interactions with the right side to the camera and screen, in which the right foot executed the steps forward or backward; and

(d) A $60 \mathrm{sec}$ series of game interactions with the left side to the camera and screen, in which the left foot executed the steps forward or backward.

During each of the three actual test series (frontal, right foot, left foot), the system was set to project on the screen 10 balls per $30 \mathrm{sec}$, for a total of 20 balls for the $60 \mathrm{sec}$ game. The participant started each game while standing on a square area marked by tape. The instructions were to step toward the target as soon as it appeared, as fast as possible. The balls appeared at random on the participant's left or right and frontal or backward direction. If the participant did not manage to touch a ball within a given time of $3 \mathrm{sec}$, the ball disappeared and another ball appeared at a random spot on the screen (50\% to the left or right in the frontal plane and forward or backward in the sagittal plane games). The median step response time was calculated out of all the steps performed in each direction (right, left, forward, backward).

\subsubsection{Activities-specific Balance Confidence (ABC) scale}

This is a 16-item self-report questionnaire that asks individuals to rate their balance confidence in performing specific ambulatory activities, on a numerical rating scale of 0-100. A score of zero represents no confidence, while a score of 100 represents complete confidence in performing the activity. The scale was found reliable in elderly and post-stroke populations [33,34], and is often used as an indication of fear of falling [35].

\subsubsection{MiniBESTest}

The original Balance Evaluation Systems Test (BESTest) was developed as a clinical balance assessment tool that aims at targeting different balance control systems, so that specific rehabilitation approaches can be designed for different balance deficits [36]. This 36-item version was later abridged into a more practical system called the Mini-BESTest [32]. This test is comprised of 14 items, retaining four out of the six balance categories (anticipatory postural adjustments, postural responses, sensory 
Table 2

RST-react outcomes in milisec

\begin{tabular}{clll}
\hline & All & $\geqslant 86$ & $\leqslant 85$ \\
\hline Forward step: & 1133 & 1178.75 & 1054 \\
Median (range) & $(866-2300)$ & $(866-2091.5)$ & $(916-2300)$ \\
Backward step: & 1083 & 1083 & 1049.5 \\
Median (range) & $(824.5-2433)$ & $(833-2433)$ & $(824.5-2200)$ \\
Sideward step: & 1037 & 1045.5 & 1028.5 \\
Median (range) & $(866-2116)$ & $(866-2116)$ & $(891.5-1750)$ \\
\hline
\end{tabular}

Table 3

Balance tests' outcomes (mean $\pm \mathrm{SD}$ )

\begin{tabular}{llcc}
\hline & All & $\geqslant 86$ & $\leqslant 85$ \\
\hline TUG $(\mathrm{sec})$ & $12.2 \pm 6.2$ & $12.7 \pm 7$ & $11 \pm 3.4$ \\
MiniBESTest score & $20.3 \pm 5.3$ & $19.3 \pm 5.2$ & $22.6 \pm 4.7$ \\
MiniBESTest $(\%)$ & $72.5 \pm 18.8$ & $69 \pm 18.7^{*}$ & $80.75 \pm 16.8$ \\
ABC $(\%)$ Mean \pm SD & $80.4 \pm 3.7$ & $80.8 \pm 14$ & $80.2 \pm 13.7$ \\
\hline
\end{tabular}

Note: $*=$ Between group t-test significant at $p<0.05$.

orientation, and balance during gait) from the original BESTest, and can be conducted within a time of 15 minutes [37].

\subsubsection{Timed Up and Go (TUG)}

This is a quick, simple, and widely-used clinical outcome measure of lower extremity function, fall risk, and mobility [38]. In this test participants are asked to stand up from sitting in a standard-height chair, walk a distance of $3 \mathrm{~m}$ (marked on the floor) at a comfortable pace, turn, walk back, and sit down again. Participants are allowed to use routine walking aids and are instructed not to use their arms to stand up. The TUG is a part of the MiniBESTest, but is often used as a stand alone test to assess functional mobility. Scoring in the MiniBESTest is on an ordinal scale, while in the TUG the number of seconds needed to complete the test is recorded with a stopwatch. Timing starts on the command "Go" and stops when the participant's back is positioned against the back of the chair after sitting down again $[39,40]$.

\subsection{Procedure}

After reading and signing the informed consent form, the participants completed a demographic questionnaire and the ABC questionnaire. They then performed the functional balance assessment utilizing the MiniBESTest (14 sub-test), including the TUG. After a 2-min rest period they completed the VRRST. The entire procedure lasted about one hour.

\subsection{Statistical analysis}

Since the outcomes of VR-RST did not present a normal distribution, non-parametric statistics were used. RST times are presented in median and range. Spearman Rank correlations were computed to describe the correlation between the VR-RST and the functional balance measurements (Mini-BEST and TUG) or and between the VR-RST and the fear of falling scale (ABC). Significance was set at $p \leqslant$ 0.05 . Benchmarks for correlations were $r \leqslant 0.35$ considered as low or weak correlations, $r$ between 0.36 to 0.67 modest or moderate correlations, and $\mathrm{r}$ between 0.68 to 0.90 as strong or high correlations, 
Table 4

Spearman correlations between various steps of VR-RST

\begin{tabular}{|c|c|c|c|c|c|c|c|c|c|}
\hline & \multicolumn{3}{|c|}{ Forward step } & \multicolumn{3}{|c|}{ Backward step } & \multicolumn{3}{|c|}{ Sideward step } \\
\hline Age/measure & All & $\geqslant 86$ & $\leqslant 85$ & All & $\geqslant 86$ & $\leqslant 85$ & All & $\geqslant 86$ & $\leqslant 85$ \\
\hline Forward step & & & & $0.60 * * *$ & $0.62 * * *$ & $0.58 *$ & $0.57 * * *$ & $0.59 * * *$ & $0.45 *$ \\
\hline Backward step & $0.85 * * *$ & $0.87 * * *$ & $0.76 * * *$ & & & & $0.57 * * *$ & $0.59 * * *$ & 0.45 \\
\hline Sideward step & $0.60 * * *$ & $0.62 * * *$ & $0.58 *$ & $0.57 * * *$ & $0.59 * * *$ & 0.45 & & & \\
\hline
\end{tabular}

Note: $*=p<0.05 ; * * p<0.01 ; * * * p<0.001$.

Table 5

Spearman correlations between VR-RST and clinical balance tests

\begin{tabular}{lccccccccc}
\hline & \multicolumn{3}{c}{ Forward step } & \multicolumn{3}{c}{ Backward step } & \multicolumn{3}{c}{ Sideward step } \\
\hline Age/measure & All & $\geqslant 86$ & $\leqslant 85$ & All & $\geqslant 86$ & $\leqslant 85$ & All & $\geqslant 86$ & $\leqslant 85$ \\
TUG & $0.46^{* * *}$ & $0.39 * * *$ & $0.59 * * *$ & $0.42^{* * *}$ & 0.32 & $0.72 * * *$ & $0.37 * *$ & $0.45^{* *}$ & 0.15 \\
MiniBESTest & $-0.52 * * *$ & $-0.46^{* * *}$ & $-0.59 * *$ & $-0.52^{* * *}$ & $-0.45^{* *}$ & $-0.61^{* *}$ & $-0.32^{* *}$ & $-0.41^{* *}$ & -0.17 \\
ABC & $-0.35^{* *}$ & $-0.35^{*}$ & -0.28 & $-0.46^{* * *}$ & $-0.43^{* *}$ & $-0.6^{* *}$ & $-0.35^{* *}$ & $-0.43 * *$ & -0.09 \\
\hline
\end{tabular}

Note: $*=p<0.05 ; * * p<0.01 ; * * * p<0.001$.

with $r$ coefficients $\geqslant 0.90$ as very high correlations [41]. While not the primary purpose of the study, age groups were compared via t-tests to assess the hypothesis that the "oldest old" would have lower outcomes compared to those of the less old.

\section{Results}

All participants completed the study. The median and range of the VR-RST scores are presented in Table 2. The means and SD scores of the clinical functional tests (Mini-BESTest and TUG) and the ABC questionnaire are presented in Table 3. The correlations between the VR-RST sub-domains, i.e., stepping forward, backward, and sideward, are all strong, and are presented in Table 4, while the correlations between the VR-RST and the clinical tests are presented in Table 5. Significant moderate to strong correlations were determined between the VR-RST in all directions and weak to moderate correlations were determined between the VR-RST and the Mini-BESTest, the TUG test, and the ABC questionnaire. The correlations between the Mini-BESTest and the forward and backward steps $(\rho=-0.52)$ were higher than the correlation between the Mini-BESTest and the sideward steps $(\rho=-0.32)$. Similarly, the correlations between the TUG test and the forward and backward steps ( $\rho=-0.46$ and -0.42 , respectively) are higher than between the TUG test and the sideward test ( $\rho=-0.37$ ). A different pattern emerged regarding the correlations between the ABC and steps in different directions, as the strongest correlation was with backward steps $(\rho=-0.46)$, whereas the correlation with the forward and sideward steps were both $\rho=-0.35$.

When comparing the groups of old ( 85 years and below) and very old adults (above 85 years), we did not find any significant differences in the TUG functional test, ABC questionnaire, or VR-RST results. However, we did find significant differences across age groups in the MiniBESTest $\left(t_{1,58}=-2.4 ; p<\right.$ $0.03)$.

\section{Discussion}

In spite of the age of the participants (nearly two-thirds were above 85 years old), no adverse effects occurred while executing the tests. The durations of the rapid steps performed within the VR-RST setup 
with the SeeMe platform, with median scores of 1133, 1083, and $1037 \mathrm{~ms}$ for forward, backward, and sideward stepping, respectively (see Table 2), are in agreement with RST to somatosensory cues by means of force plate measurement [19]. The VR-RST scores appear to be very similar to the outcomes of the choice reaction test in the frontal plane performed by 104 elderly individuals in an Australian study, which revealed mean total step times equal to $1231 \pm 242 \mathrm{~ms}$ for fallers and $1113 \pm 151$ for non-fallers [28]. The values of the non-fallers in the latter study are within the range of the findings in our sample, in which two-thirds were comprised of non-fallers.

Step durations in the current study seem to be moderately to strongly associated with commonly-used clinical measures of balance performance in the elderly. The strongest association was with the MiniBESTest, which provides a comprehensive measure of balance in the elderly. The Spearman correlations found in our study of the RST with the TUG test and the ABC questionnaire were stronger than those found in a study of 167 elderly adults with a 10-year younger mean age than in our sample, which used a different version of the RST, averaging $\rho=0.346$ and 0.321 , respectively [42]. However, in the latter version of the RST, a different outcome measure was used, i.e., the total time of 24 steps in forward, backward, and sideward directions, and the response was performed to the experimenters' verbal commands rather than to visual cues.

Several sources of information indicate that elderly persons are more likely to experience posterior rather than anterior or lateral falls. For example, in a study of 242 older adults (mean age $80 \pm 4.4$ years), it was found that reactions to perturbations in the posterior direction best discriminated between those who reported falling in the past 12 months and those who did not [43]. In an earlier study that examined protective mechanisms while falling, it was determined that pelvic impact was involved in more than $90 \%$ of the posterior falls, but in only $23 \%$ of the lateral falls and in none of the anterior falls [44]. Based on these findings, it may be expected that the elderly will develop a more prominent fear of falling backward rather than towards other directions, as is reflected in our finding of stronger negative association between the backward steps in the VR-RST and the total ABC score (Table 5). Those who have a faster backward step response appear to be more confident in keeping their balance while backward stepping.

The TUG involves mostly locomotor activity in the posterior-anterior plane. Similarly, the MiniBESTest's score is composed of 14 tasks that represent a variety of activities, with only two of them in the lateral plane [34]. The stronger association of these tests with response time in forward and backward step execution using the VR-RST is another indication for the validity of the proposed VR assessment method.

The lack of differences in the VR-RST between the old and "oldest old" groups in most variables as revealed in our study is noteworthy, since research typically indicates a deterioration in balance capabilities with aging $[45,46]$. One reason for the lack of such a finding in our sample might be the participants' relatively high degree of functioning, with only one-third having experienced falls in the previous year.

\section{Conclusions}

The VR-RST system described in this study appears to be a safe and valid measurement device in elderly ambulatory and independent individuals living in a community residential home. The fast-step duration times measured by means of the VR-RST system in this sample of older adults exhibited moderate significant correlations with functional balance tests, and were within the range of force plate measurements in other studies for a similar task. Therefore, based on these results, we suggest that the VR-RST may be a useful tool for clinicians working with a geriatric population, or any other population experiencing balance disorders. Future studies are warranted to evaluate the repeatability of results in 
the same participants, as well as the sensitivity and specificity for fall detection. Other studies evaluating the responsiveness of the VR-RST are also needed, and their results should, again, be compared to the findings of clinical tests. If satisfactory outcomes are revealed, the VR-RST may be further implemented as a tele-measurement system for balance assessment, which may save administration costs as well as increase the individual's independence regarding his or her assessment and training process.

\section{Conflict of interest}

The authors declare no conflict of interest regarding the publication of this study. The first and third authors are academic researchers, and the second author was at the time of study a graduate student performing her thesis research.

\section{References}

[1] Centers for Disease Control and Prevention (CDC), National Center for Injury Prevention and Control. Web - based Injury Statistics Query and Reporting System (WISQARS). Older adult falls. http://www.cdc.gov/HomeandRecreationalSafety/Falls/adultfalls.html.

[2] Sterling DA, O'Connor JA, Bonadies J. Geriatric falls: Injury severity is high and disproportionate to mechanism. Journal of Trauma - Injury, Infection and Critical Care. 2001; 50(1): 16-119.

[3] Alexander BH, Rivara FP, Wolf ME. The cost and frequency of hospitalization for fall - related injuries in older adults. American Journal of Public Health. 1992; 82(7): 1020-1023.

[4] Rao SS. Prevention of falls in older patients. American Family Physician. 2005; 72(1): 81-88.

[5] Stevens JA, Corso PS, Finkelstein EA, Miller TR. The costs of fatal and non-fatal falls among older adults. Injury Prevention. 2006; 12(5): 290-295.

[6] Centers for Disease Control and Prevention CDC, Older Adult Falls: Get the Facts Online: http://www.cdc.gov/homeandrecreationalsafety/falls/adultfalls.html.

[7] U.S. Census Bureau, 2011, Age and sex composition: 2010, by LM Howden and JA Meyer, 2010 Census Briefs, C2010BR-03, available at http://www.census.gov/prod/cen2010/briefs/c2010br-03.pdf.

[8] Tinetti ME, Kumar C. The patient who falls. Journal of the American Medical Association. 2010; 303(3): 258-266.

[9] Horak FB. Postural orientation and equilibrium: what do we need to know about neural control of balance to prevent falls? Age Ageing. 2006; 35(2): ii7-ii11.

[10] Zajonc TP, Roland PS. Vertigo and motion sickness. Part I: vestibular anatomy and physiology. Ear, Nose \& Throat Journal. 2005; 84: 581-584.

[11] Herdman S. Vestibular rehabilitation, 3rd edn. F.A. Davis, Philadelphia, PA, 2007.

[12] Shumway-Cook A, Woollacott MH. Motor control: Translating research into clinical practice, 4th edn. Lippincott, Philadelphia, PA, 2011.

[13] Huxham F, Goldie P, Patela A. Theoretical considerations in balance assessment. Australian Journal of Physiotherapy. 2001; 47: 89-100.

[14] Maki BE, McIlroy WE. Control of rapid limb movements for balance recovery: age-related changes and implications for fall prevention. Age and Ageing. 2006; 35(2): ii12-ii18.

[15] Patla E, Frank JS, Winter DA et al. Age-related changes in balance control system: initiation of stepping. Clinical Biomechanics. 1993; 8: 179-184.

[16] Maki E, McIlroy WE. Effects of aging on control of stability. In: A textbook of audiological medicine: Clinical aspects of hearing and balance. Luxon L, Martini A, Furman J, Stephens D, eds, Martin Dunitz Publishers, London, 2003; 671-690.

[17] Mancini M. Horak FB. The relevance of clinical balance assessment tools to differentiate balance deficits. European Journal of Physical and Rehabilitation Medicine. 2010; 46(2): 239-249.

[18] Schoene D, Smith ST, Davies TA et al. A Stroop Stepping Test (SST) using low-cost computer game technology discriminates between older fallers and non-fallers. Age and Ageing. 2014; 43(2): 285-289. doi: 10.1093/ageing/aft157.

[19] Melzer I, Kurz D, Shahar M et al. Application of the voluntary step execution test to identify elderly fallers. Age and Ageing. 2007; 36: 532-537.

[20] Melzer I, Kurz I, Sarid O, Jette AM. Relationship between self-reported function and disability and balance performance measures in the elderly. Journal of Rehabilitation Research \& Development. 2007; 44(5): 685-692. 
[21] Melzer I, Shtilman I, Rosenblatt N, Oddsson LIE. Reliability of voluntary step execution behavior under single and dual task conditions. Journal of NeuroEngineering and Rehabilitation. 2007; 4: 16.

[22] Lord SR, Fitzpatrick RC. Choice stepping reaction time: A composite measure of falls risk in older people. The Journals of Gerontology Series A: Biological Sciences and Medical Sciences. 2001; 56(10): M627-M632.

[23] Yamaji S, Demura S, Sohee S, Uchiyama M. Reliability of a new rapid step test for older women and its relationship with fall risk and leg muscle function. Health. 2012; 4(1): 703-711. http://dx.doi.org/10.4236/health.2012.429110.

[24] Laufer Y, Sugarman H, Burstin A, Brown R. Age, but not sit or stance, affects rapid reaching movement time to virtual objects in response to a simple or choice cue. Presented at the Joint World Congress of ISPGR and Gait \& Mental Function, Trondheim. 2012; http://ispgr.org/fileadmin/templates/_img/norway2012/ISPGR_Detailed_Program_2012_ 04_26.pdf.

[25] Hutzler Y. Virtual reality and exergaming in rehabilitation: Scientific evidence and practical impact on adapted physical activity (APA), Spor Bilimleru Dergisi. Hacetteppe Journal of Sport Sciences. 24(2): 80-84.

[26] Laufer Y, Dar G, Kodesh E. Does a Wii-based exercise program enhance balance control of independently functioning older adults? A systematic review. Clinical Interventions in Aging. 2014; 9: 1803-1813.

[27] Li Z, Han XG, Sheng J, Ma SJ. Virtual reality for improving balance in patients after stroke: A systematic review and meta-analysis. Clinical Rehabilitation. 3 Jul 2015. pii: 0269215515593611. [Epub ahead of print].

[28] Ejupi A, Brodie M, Gschwind YJ et al. Choice stepping reaction time test using exergame technology for fall risk assessment in older people. Conf Proc IEEE Eng Med Biol Soc. 2014; 2014: 6957-60. doi: 10.1109/EMBC.2014.6945228.

[29] Brown R, Burstin A, Laufer Y. Age but not sit or stance affects rapid reaching movement time to virtual objects in response to a simple or go no-no task. PM\&R Journal. 2014; 6(8, 2): S126-S127.

[30] Laufer Y, Burstein A, Brown R, Korsensky O, Hutzler Y. Rapid stepping time on virtual objects correlates with measures of balance and fear of falling in elderly individuals. WCPT Congress, Physiotherapy. 2015; 101, Supplement 1 eS189. doi: http://dx.doi.org/10.1016/j.physio.2015.03.349.

[31] O'Hoski S, Sibley KM, Brooks D, Beauchamp MK. Construct validity of the BESTest, mini-BESTest and briefBESTest in adults aged 50 years and older. Gait \& Posture. 2015; 42(3): 301-305. DOI: http://dx.doi.org/10.1016/j.gaitpost.2015. 06.006.

[32] Franchignoni F, Horak F, Godi M et al. Using/psychometric techniques to improve the balance evaluation systems test: The mini-BESTest. Journal of Rehabilitation Medicine. 2010; 42(4): 323-231. doi: 10.2340/16501977-0537.

[33] Powell LE, Myers AM. The activities-specific balance confidence (ABC) scale. Journal of Gerontology, Series A: Biological Sciences \& Medical Sciences. 1995; 50(1): 28-34.

[34] Botner EM, Miller WC, Eng JJ. Measurement properties of the Activities-specific Balance Confidence Scale among individuals with stroke. Disability \& Rehabilitation. 2005; 27(4): 156-163.

[35] Klima DW, Newton RA, Keshner EA, Davey A. Fear of falling and balance ability in older men: the priest study. Journal of Aging and Physical Activity. 2012; 21(4): 375-386. Epub 2012 Nov 19.

[36] Horak R, Wrisley DM, Frank J. The Balance Evaluation Systems Test (BESTest) to differentiate balance deficits. Physical Therapy. 89(5): 484-498.

[37] Godi M, Franchignoni F, Caligari M et al. Comparison of reliability, validity, and responsiveness of the miniBESTest and Berg Balance Scale in patients with balance disorders. Physical Therapy. 2013; 93(2): 158-67. doi: 10.2522/ptj.20120171.

[38] Podsiadlo D, Richardson S. The timed 'Up \& Go': a test of basic functional mobility for frail elderly persons. Journal of the American Geriatric Society. 1991; 39: 142-148. [PubMed].

[39] Giladi N, Herman T, Reider-Groswasser II et al. Clinical characteristics of elderly patients with a cautious gait of unknown origin. Journal of Neurology. 2005; 252: 300-306.

[40] Vereeck L, Wuyts F, Truijen S, Van de Heyning P. Clinical assessment of balance: normative data, and gender and age effects. International Journal of Audiology. 2008; 47: 67-75.

[41] Taylor R. Interpretation of the correlation-coefficient - A basic review. Journal of Diagnostic Medical Sonography. 1990; 6: $35-39$

[42] Cho B, Scarpace D, Alexander NB. Tests of stepping as indicators of mobility, balance, and fall risk in balance-impaired older adults. Journal of the American Geriatrics Society. 2004; 52: 1168-1173.

[43] Sturnieks DL, Menant J, Delbaere K et al. Force controlled balance perturbations associated with falls in older people: a prospective cohort study. PLoS One. 9 Aug 2013; 8(8): e70981. doi: 10.1371/journal.pone.0070981.

[44] Hsiao ET, Robinovitch SN. Common protective movements govern unexpected falls from standing height. Journal of Biomechanics. 1998; 31(1): 1-9.

[45] Jiang J, Long J, Ling W et al. Incidence of fall-related injury among old people in mainland China. Archives of Gerontolology and Geriatrics. 2015; 61(2): 131-139. doi: 10.1016/j.archger.2015.06.003.Epub 2015 Jun 12.

[46] Cattagni T, Scaglioni G, Cornu $C$ et al. What are the effects of the aging of the neuromuscular system on postural stability? Geriatrics Psychol Neuropsychiatr Vieil. 1 Dec 2015; 13(4): 363-380. 